\title{
Effectiveness of transcranial direct current stimulation preceding cognitive behavioural management for chronic low back pain: sham controlled double blinded randomised controlled trial
}

\author{
Kerstin Luedtke, ${ }^{1}$ Alison Rushton, ${ }^{2}$ Christine Wright, ${ }^{2}$ Tim Jürgens, ${ }^{1}$ Astrid Polzer, ${ }^{1}$ \\ Gerd Mueller, ${ }^{3}$ Arne May ${ }^{1}$
}

${ }^{1}$ Department of Systems

Neuroscience, University

Medical Centre Hamburg-

Eppendorf, Martinistr. 52,

20246 Hamburg, Germany

${ }^{2} S c h o o l$ of Sport, Exercise and

Rehabilitation Sciences, College

of Life and Environmental

Sciences, University of

Birmingham, Edgbaston,

Birmingham, B15 2TT, UK

3Backpain Clinic "Am Michel",

Ludwig-Erhard-Str.18, 20459

Hamburg, Germany

Correspondence to:

A Maya.may@uke.de

Additional material is published online only. To view please visit the journal online (http:// dx.doi.org/10.1136/bmj.h1618) Cite this as: $B M J$ 2015;350:h1640 doi: 10.1136/bmj.h1640

Accepted: 23 February 2015

\section{ABSTRACT}

OBJECTIVE

To evaluate the effectiveness of transcranial direct current stimulation alone and in combination with cognitive behavioural management in patients with non-specific chronic low back pain.

\section{DESIGN}

Double blind parallel group randomised controlled trial with six months' follow-up conducted May 2011-March 2013. Participants, physiotherapists, assessors, and analyses were blinded to group allocation.

SETTING

Interdisciplinary chronic pain centre.

PARTICIPANTS

135 participants with non-specific chronic low back pain $>12$ weeks were recruited from 225 patients assessed for eligibility.

\section{INTERVENTION}

Participants were randomised to receive anodal (20 minutes to motor cortex at $2 \mathrm{~mA}$ ) or sham transcranial direct current stimulation (identical electrode position, stimulator switched off after 30 seconds) for five consecutive days immediately before cognitive behavioural management (four week multidisciplinary programme of 80 hours).

\section{MAIN OUTCOMES MEASURES}

Two primary outcome measures of pain intensity (0-100 visual analogue scale) and disability (Oswestry disability index) were evaluated at two primary endpoints after stimulation and after cognitive behavioural management.

\section{WHAT IS ALREADY KNOWN ON THIS TOPIC}

Numerous small studies have suggested that transcranial direct current stimulation can reduce chronic pain

Until now evidence from appropriately powered randomised controlled trials has been lacking

Systematic reviews and meta-analyses indicated a small beneficial effect but also highlighted the high risk of bias of existing trials

\section{WHAT THIS STUDY ADDS}

This is the first adequately powered trial, with low risk of bias, to evaluate transcranial direct current stimulation for pain reduction

Transcranial direct current stimulation over the motor cortex has no benefit for the reduction of pain and disability in patients with non-specific chronic low back pain Furthermore, transcranial direct current stimulation applied immediately before a cognitive behavioural group intervention does not influence the outcome of the intervention

\section{RESULTS}

Analyses of covariance with baseline values (pain or disability) as covariates showed that transcranial direct current stimulation was ineffective for the reduction of pain (difference between groups on visual analogue scale $1 \mathrm{~mm}$ ( $99 \%$ confidence interval $-8.69 \mathrm{~mm}$ to $6.3 \mathrm{~mm} ; \mathrm{P}=0.68)$ ) and disability (difference between groups 1 point ( -1.73 to 1.98; $\mathrm{P}=0.86)$ ) and did not influence the outcome of cognitive behavioural management (difference between group $3 \mathrm{~mm}$ (-10.32 $\mathrm{mm}$ to $6.73 \mathrm{~mm})$; $\mathrm{P}=0.58$; difference between groups on Oswestry disability index 0 point ( -2.45 to 2.62 ); $\mathrm{P}=0.92$ ). The stimulation was well tolerated with minimal transitory side effects.

\section{CONCLUSIONS}

This results of this trial on the effectiveness of transcranial direct current stimulation for the reduction of pain and disability do not support its clinical use for managing non-specific chronic low back pain.

\section{TRIAL REGISTRATION}

Current controlled trials ISRCTN89874874.

\section{Introduction}

Low back pain is one of the most prevalent and expensive musculoskeletal conditions. ${ }^{1}$ It is generally benign, ${ }^{2}$ with $74-89 \%$ patients recovering after three to six months, ${ }^{3}$ though about $9-28 \%$ develop chronic pain. ${ }^{4-7}$ Non-specific chronic low back pain does not have a defined source, ${ }^{78}$ and the pathogenesis is not fully understood. In the absence of a peripheral pathology, central sensitisation has been hypothesised to explain the development and maintenance of nonspecific chronic low back pain. ${ }^{910}$ Main mechanisms are an increased release of excitatory neurotransmitters at spinal level, influencing pain perception via the spinothalamic pathway and altered top down pain control from the brain. ${ }^{11} 12$

International guidelines recommend multimodal cognitive behavioural therapy programmes, defined as structured interventions designed to modify dysfunctional thinking and behaviour, ${ }^{13}$ as the most effective available intervention for reduction of pain and disability. ${ }^{814-16}$ A recent systematic review identified moderate evidence for the short term effectiveness of cognitive behavioural interventions. ${ }^{17}$ The pooled effect size for pain reduction compared with other active interventions, however, was low $(12 \mathrm{~mm}$ on a $0-100 \mathrm{~mm}$ visual analogue scale). Adjunct approaches that modulate excitability of the central nervous system have been proposed to enhance the effects of cognitive 
behavioural management on non-specific chronic low back pain. ${ }^{18-20}$

Transcranial direct current stimulation is a non-invasive technique to electrically stimulate the brain. It can be applied to different target areas on the skull by attachment of sponge electrodes soaked in saline solution. It is hypothesised that this influences cortical excitability by inducing positively or negatively charged currents through the skull, ${ }^{21}$ thereby modulating a widespread neural network of areas associated with pain processing including the thalamic nuclei, limbic system, brainstem nuclei, and spinal cord. ${ }^{22}$ Pain reducing effects of transcranial direct current stimulation are attributed to modulation of the endogenous opioid system, ${ }^{23}$ emotional appraisal of pain, ${ }^{24}$ and descending pain inhibition. ${ }^{23-25}$

Systematic reviews and meta-analyses on the effectiveness of anodal transcranial direct current stimulation reported a small pain reducing effect with stimulation of the motor cortex. ${ }^{2627}$ The overall level of evidence, however, was low to very low ${ }^{2627}$ because of an overall unclear or high risk of bias and inadequate sample sizes in all included trials. Recent research reported that pain reduction after traditional interventions was enhanced by the application of transcranial direct current stimulation as an adjuvant intervention-that is, as a priming technique to repetitive transcranial magnetic stimulation, ${ }^{28}$ combined with transcutaneus electrical nerve stimulation $^{29}$ or with a multidisciplinary programme. ${ }^{30}$

We evaluated the effectiveness of transcranial direct current stimulation on non-specific chronic low back pain and investigated its use as an adjunct intervention before cognitive behavioural management.

\section{Methods}

Study design and participants

This double blind parallel group randomised controlled trial was conducted in Germany. Trial design and its reporting followed the internationally recognised recommendations published by the CONSORT group, ${ }^{31}$ the International Conference on Harmonisation of Technical Requirements for Registration of Pharmaceuticals for Human Use, ${ }^{32}$ and the World Medical Association's Declaration of Helsinki. ${ }^{33}$

Participants were adults aged 18-65 with non-specific chronic low back pain persisting for more than 12 weeks as defined in the European guidelines ${ }^{8}$ who met the eligibility criteria for cognitive behavioural management at a back pain clinic in Germany. All participants presented with a minimum of $15 \mathrm{~mm}$ on a 0-100 visual analogue scale for pain or 8 points on the Oswestry disability index. Eligibility for the cognitive behavioural management programme required the patient to understand and speak German. Patients had to be motivated to return to work and had to be physically fit enough to tolerate a four week physical training programme. An orthopaedic consultant, a psychologist, and a physiotherapist confirmed a participant's eligibility for cognitive behavioural management by following a standard screening procedure. Participants were excluded if they presented with other chronic pain syndromes, neurological disease, or psychiatric disease; had had spinal surgery in the previous six months; were pregnant or trying to become pregnant; or misused alcohol, drugs, or prescription drugs.

\section{Randomisation and blinding}

Randomisation to anodal or sham stimulation was conducted in permuted blocks of 20 to allow for equal numbers in each study arm at various time points ${ }^{34-37}$ and stratified for baseline pain intensity. ${ }^{38}$ We randomised 160 stimulation codes (80 triggering active stimulation, 80 triggering sham stimulation) by custom written software into two separate lists for low (20-50 $\mathrm{mm})$ and high (51-100 mm) pain intensity at baseline on a visual analogue scale. An independent researcher created the randomisation lists. To achieve allocation concealment the recruiter provided participants with the next unused stimulation code from the randomised lists. The recruiter had no access to the randomisation list. Blinding of participants and the treating physiotherapist was achieved by using a sham paradigm identical to the anodal stimulation procedure except that the direct current stimulator automatically switched off after 30 seconds after slowly reducing the stimulation intensity ( 5 second fade out). Stimulation mode (anodal/sham) was preprogrammed with five digit stimulation codes that triggered the active or sham procedure. The machine display continued to indicate the time and the impedance in the same manner for both procedures. Because of the initial brief stimulation period, associated skin sensation, and identical machine display, this method has previously been regarded as a reliable placebo condition for double blind trial designs. ${ }^{39-41}$ More recent debate, however, questioned the reliability of participant and assessor blinding with this sham paradigm. ${ }^{42}$ We therefore evaluated the success of blinding by asking participants after each stimulation session which type of stimulation they believed they had received. Additionally, the assessor recorded which stimulation type she believed the participant had received. To evaluate whether participants and investigator could guess the stimulation type better than would be expected by chance, we determined the $\kappa$ coefficient of agreement for each day of stimulation. ${ }^{42} 43$ Blinding during data analysis was achieved by labelling participants "group A" and "group B" (performed by an independent researcher).

\section{Interventions \\ Transcranial direct current stimulation}

Participants received 20 minutes of anodal or sham stimulation over the left motor cortex with an intensity of $2 \mathrm{~mA}$ on five consecutive days. We chose this stimulation paradigm based on results from our systematic review, which identified it as the most effective in chronic pain trials with the lowest risk of bias. ${ }^{27}$ Transcranial direct current stimulation was produced by a small battery driven stimulator device and applied to the skull via saline solution (0.9\%) soaked sponge electrodes $\left(7 \times 5 \mathrm{~cm}=35 \mathrm{~cm}^{2}\right)$. The anode was 
placed over the left motor cortex, while the cathode was placed supraorbitally on the contralateral side, and both were held in place by elastic bandages. The electricity was slowly increased to $2 \mathrm{~mA}$ at the beginning of the stimulation (eight seconds fade in) and slowly decreased at the end of the stimulation (eight seconds fade out) to reduce skin sensations underneath the electrodes. ${ }^{44}$ Single pulse transcranial magnetic stimulation (Magstim Company, Dyfed, UK) was applied to accurately determine the location of the left motor cortex (abductor digiti minimi) with a standard protocol. 4546

\section{Cognitive behavioural management}

Immediately after the stimulation period all participants started a cognitive behavioural management programme. A maximum of eight patients per group received physically challenging sessions, including cardiovascular exercises, machine assisted muscle strength training, specific muscle stabilisation exercises for the trunk muscles, and work hardening sessions, as well as educational sessions on the neurophysiology of pain, pain coping strategies, and relaxation classes. Patients attended five hours daily for four weeks as outpatients. An interdisciplinary team of orthopaedic consultants, physiotherapists, psychologists, and sports scientists delivered the cognitive behavioural management programme.

\section{Outcome measures}

Transcranial direct current stimulation and cognitive behavioural management have different suggested roles within the management of non-specific chronic low back pain. Transcranial direct current stimulation directly targets pain processing areas within the brain, aiming to reduce pain intensity; this was therefore essential as a primary outcome measure. Cognitive behavioural management targets disability, cognitions, and beliefs associated with chronic pain and other psychosocial aspects of the pain experience and might not necessarily result in a reduction of pain intensity. ${ }^{47-49} \mathrm{To}$ deal with the research objective of the combined effect of transcranial direct current stimulation and cognitive behavioural management, we therefore also selected disability (Oswestry disability index) as a primary outcome measure.

The initiative on methods, measurement, and pain assessment in clinical trials defined the following outcome domains as important for chronic pain trials: pain, physical functioning, emotional functioning, participants' ratings of improvement and satisfaction, symptoms and adverse events, and participants' disposition. ${ }^{50}$ We also selected the following secondary outcome measures according to their evidence base for evaluating non-specific chronic low back pain and their measurement properties: Funktionsfragebogen Hannover (Hannover functional ability questionnaire), ${ }^{51}$ "bothersomeness,"52 RAND 36-item health survey, ${ }^{53}$ fear avoidance beliefs questionnaire, ${ }^{54}$ hospital anxiety and depression score, ${ }^{55}$ and patient perceived satisfactory improvement. ${ }^{56}$
Participants were assessed immediately before the first session of transcranial direct current stimulation (baseline), 24 hours after the final stimulation (primary endpoint 1), on the last day of cognitive behavioural management (primary endpoint 2), and four weeks, 12 weeks, and 24 weeks after cognitive behavioural management to observe longer term treatment effects (fig 1). Based on the two primary outcome measures and the two primary endpoints, we calculated the sample size at an $\alpha$ level of 0.0125 (90\% power). ${ }^{5758}$ Based on recommendations for a minimum clinically relevant change of $15 \mathrm{~mm}$ on a $0-100 \mathrm{~mm}$ visual analogue scale for pain ${ }^{59}$ and 8 points on the Oswestry disability index, ${ }^{60}$ and allowing for a dropout rate of $12 \%$ after transcranial direct current stimulation ${ }^{61}$ and a further $16 \%$ after the cognitive behavioural management, ${ }^{62}$ we required 135 participants. The calculated effect sizes were 0.79 for visual analogue scale and 0.75 for Oswestry disability index and were regarded as medium to large $\mathrm{e}^{63}$ ( $\mathrm{G}^{\star}$ Power Version 3.1.2).

To document any observed side effects, after each stimulation session participants were required to complete a standardised questionnaire routinely used for transcranial direct current stimulation trials. ${ }^{4564}$ All procedures were tested in a feasibility trial conducted before the main data collection phase.

\section{Data analysis}

We collected participants' characteristics and baseline values for primary and secondary outcome measures to allow comparisons between groups at baseline.

Primary analyses were conducted at an $\alpha$ level of $\mathrm{P}<0.0125$ as described for the sample size calculation. ${ }^{65}$ To evaluate the effectiveness of transcranial direct current stimulation, we fitted a general linear model for each of the two primary outcome measures (visual analogue scale, Oswestry disability index) at each of the two primary endpoints (after stimulation and after cognitive behavioural management) using values after the intervention as the dependent variable and values before the intervention as covariates (analysis of covariance

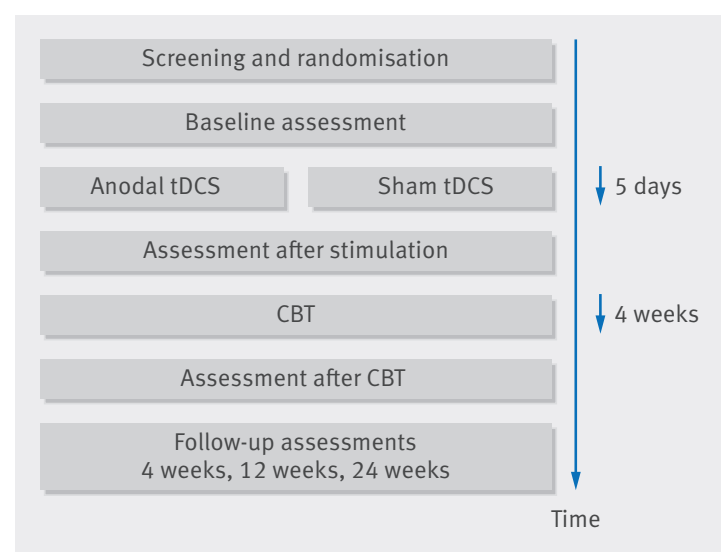

Fig 1 | Flowchart for trial of effectiveness of anodal or sham transcranial direct current stimulation (tDCS) alone and before cognitive behavioural management (CBT) for patients with chronic low back pain 
(ANCOVA)). ${ }^{6667}$ We reported results as $F$ values (with degrees of freedom) and $\mathrm{P}$ values as well as $99 \%$ confidence intervals for differences between groups with Sidak adjustment for multiple comparisons. ${ }^{68}$

We conducted secondary analyses at an exploratory level and did not require further adjustment of the $\alpha$ level for multiple testing. ${ }^{65}$ To evaluate the intervention effect on the primary outcome measures over time, we fitted a separate multilevel model for pain and disability, including all assessment time points. All secondary outcome measures were entered into the statistical model in

\begin{tabular}{|c|c|c|}
\hline \multicolumn{3}{|c|}{ Assessed for eligibility $(n=255)$} \\
\hline & & $\begin{array}{l}\text { Excluded }(n=120) \text { : } \\
\text { Did not meet inclusion criteria }(n=23): \\
\text { Pain }<15 \text { VAS and ODI }<8 \text { at baseline }(n=12) \\
\text { Surgery }<6 \text { months ago }(n=11) \\
\text { Declined to participate }(n=97)\end{array}$ \\
\hline \multicolumn{3}{|c|}{ Randomised $(n=135)$} \\
\hline & $\downarrow$ & 7 \\
\hline \multicolumn{2}{|c|}{$\begin{array}{l}\text { Allocated to anodal stimulation }(n=67) \\
\text { Received allocated intervention }(n=67)\end{array}$} & $\begin{array}{l}\text { Allocated to sham stimulation }(n=68) \\
\text { Received allocated intervention }(n=68)\end{array}$ \\
\hline After stimulation & 1 & $\downarrow$ \\
\hline \multicolumn{2}{|c|}{$\begin{array}{l}\text { Lost to follow-up } 1 \text { (missing data) } \\
\text { (VAS } n=5 ; \text { ODI } n=4) \\
\text { Discontinued intervention (skin reaction, } \\
\text { conflicting appointments) }(n=2)\end{array}$} & $\begin{array}{l}\text { Lost to follow-up } 1 \text { (missing data) } \\
\text { (VAS } n=4 ; \text { ODI } n=5) \\
\text { Discontinued intervention (surgery, conflicting } \\
\text { appointments) }(n=2)\end{array}$ \\
\hline & $\downarrow$ & $\downarrow$ \\
\hline \multicolumn{2}{|c|}{$\begin{array}{l}\text { Analysis } 1(\text { VAS } n=60 ; \\
\text { Excluded from analysis }(n=0)\end{array}$} & $\begin{array}{l}\text { Analysis } 1(\text { VAS } n=62 ; \text { ODI } n=61) \\
\text { Excluded from analysis }(n=0)\end{array}$ \\
\hline After CBT & & $\downarrow$ \\
\hline \multicolumn{2}{|c|}{$\begin{array}{l}\text { Lost to follow-up } 2 \text { (missing data) } \\
\text { (VAS } n=7 ; \text { ODI } n=9) \\
\text { Discontinued intervention }(n=0)\end{array}$} & $\begin{array}{l}\text { Lost to follow-up } 2 \text { (missing data) } \\
\text { (VAS } n=7 ; \text { ODI } n=6 \text { ) } \\
\text { Discontinued intervention (surgery, acute } \\
\text { sciatica, influenza) }(n=3)\end{array}$ \\
\hline & & $\downarrow$ \\
\hline \multicolumn{2}{|c|}{$\begin{array}{l}\text { Analysis } 2(\text { VAS } n=60 ; \text { ODI } n=53) \\
\text { Excluded from analysis }(n=0)\end{array}$} & $\begin{array}{l}\text { Analysis } 2(\text { VAS } n=58 ; \text { ODI } n=54) \\
\text { Excluded from analysis }(n=0)\end{array}$ \\
\hline 4 weeks after & & $\downarrow$ \\
\hline \multicolumn{2}{|c|}{$\begin{array}{l}\text { Lost to follow-up } 3 \text { (missing data) } \\
\text { (VAS } n=13 ; \text { ODI } n=12 \text { ) }\end{array}$} & $\begin{array}{l}\text { Lost to follow-up } 3 \text { (missing data) } \\
\text { (VAS } n=12 ; \text { ODI } n=12 \text { ) }\end{array}$ \\
\hline & $\downarrow$ & $\downarrow$ \\
\hline \multicolumn{2}{|c|}{$\begin{array}{l}\text { Analysis } 3(\text { VAS } n=54 ; O D I n=55) \\
\text { Excluded from analysis }(n=0)\end{array}$} & $\begin{array}{l}\text { Analysis } 3(\text { VAS } n=56 ; O D I n=56) \\
\text { Excluded from analysis }(n=0)\end{array}$ \\
\hline 12 weeks after & & 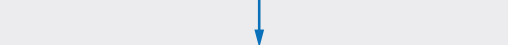 \\
\hline \multicolumn{2}{|c|}{$\begin{array}{l}\text { Lost to follow-up } 4 \text { (missing data) } \\
\text { (VAS } n=14 ; \text { ODI } n=15 \text { ) }\end{array}$} & $\begin{array}{l}\text { Lost to follow-up } 4 \text { (missing data) } \\
\text { (VAS n=20; ODI } n=19 \text { ) }\end{array}$ \\
\hline & $\downarrow$ & $\downarrow$ \\
\hline \multicolumn{2}{|c|}{$\begin{array}{l}\text { Analysis } 4(\text { VAS } n=53 \text {; ODI } n=52) \\
\text { Excluded from analysis }(n=0)\end{array}$} & $\begin{array}{l}\text { Analysis } 4(\text { VAS } n=48 ; \text { ODI } n=49) \\
\text { Excluded from analysis }(n=0)\end{array}$ \\
\hline \multicolumn{2}{|l|}{24 weeks after } & $\downarrow$ \\
\hline \multicolumn{2}{|c|}{$\begin{array}{l}\text { Lost to follow-up } 5 \text { (missing data) } \\
\text { (VAS n=20; ODI n=19) }\end{array}$} & $\begin{array}{l}\text { Lost to follow-up } 5 \text { (missing data) } \\
\text { (VAS } n=26 ; \text { ODI } n=26 \text { ) }\end{array}$ \\
\hline & $\downarrow$ & $\downarrow$ \\
\hline $\begin{array}{l}\text { Analysis } 5 \text { (VAS } \\
\text { Excluded from a }\end{array}$ & $\begin{array}{l}\text { ODI } n=48) \\
(n=0)\end{array}$ & $\begin{array}{l}\text { Analysis } 5(\text { VAS } n=42 \text {; ODI } n=42) \\
\text { Excluded from analysis }(n=0)\end{array}$ \\
\hline
\end{tabular}

Fig 2 Flow of patient inclusion and numbers of participants available for analysis at each prespecified time point for both primary outcome measures (Oswestry disability index (ODI) and visual analogue scale for pain (VAS)) in trial of effectiveness of anodal or sham transcranial direct current stimulation (tDCS) before cognitive behavioural management (CBT) for patients with chronic low back pain a stepwise manner (forward approach) and removed if not significant. ${ }^{69}$ These factors, as well as group (anodal, sham), were added to the model as fixed effect factors while time, time ${ }^{2}$, and time ${ }^{3}$ were entered as random factors to model a non-linear trend over time. ${ }^{70}$

To explore the effect of anodal stimulation compared with sham stimulation on each of the secondary outcome measures at the primary endpoints after stimulation and after cognitive behavioural management, we used analysis of covariance using baseline values as covariates. The secondary outcome measures were further evaluated by building a multilevel model with time, time, ${ }^{2}$ and time ${ }^{3}$ as random factors and group (active, sham) as a fixed effect factor. We conducted Bonferroni corrected post hoc $t$ tests if we identified a significant interaction of group by time for any secondary outcome measure. ${ }^{68}$ All analyses were performed with SPSS 18 for Apple Macintosh (SPSS, Chicago, IL).

\section{Results}

Recruitment took place from May 2011 to March 2013. All consecutive patients who were waiting for the cognitive behavioural management programme $(n=255)$ were contacted by telephone and assessed for eligibility to recruit the required 135 participants. Of 232 eligible patients, 97 declined to participate because of the additional time and travel required for the extra five visits to the back pain clinic for the stimulation. Figure 2 shows the numbers of participants analysed at each time point. ${ }^{71}$

Table 1 shows the baseline characteristics by intervention group, which indicate representativeness of participants in comparison with internationally published trials evaluating cognitive behavioural management interventions in non-specific chronic low back pain. ${ }^{6272-74}$ Table 2 presents baseline data on primary and secondary outcome measures.

None of the participants switched group. Missing data at the two primary endpoints were balanced across groups. The total amount of missing data was less than $10 \%$ after stimulation and further $3 \%$ (pain) and 10\% (disability) after cognitive behavioural management. This amount was within the anticipated dropout rate for the sample size calculation. Reasons provided for discontinuing the trial were not based on clinical data but on additional time and travel. Data were therefore considered to be missing at random. Following published recommendations, data met the two main principles for intention to treat analysis. ${ }^{7576}$

There were no significant differences between groups for pain and Oswestry disability index at the two primary endpoints after stimulation and after cognitive behavioural management. Table 3 and figs 3 and 4 show mean values and results of statistical tests.

When we looked at the effects on pain and Oswestry disability index over time, we found no significant interactions between the factors group and time using a multilevel model analysis on visual analogue scale for pain (95\% confidence interval for the estimates of group ${ }^{\star}$ time as a fixed effect was -0.84 to $0.20 ; \mathrm{P}=0.23$ ) or Oswestry disability index ( -0.16 to $0.11 ; \mathrm{P}=0.72)$ (table 4). Stepwise building of the multilevel models for pain 


\begin{tabular}{|c|c|c|}
\hline & \multicolumn{2}{|c|}{ Intervention group } \\
\hline & Anodal $(n=67)$ & Sham $(n=68)$ \\
\hline Women & $33(49)$ & $30(44)$ \\
\hline \multicolumn{3}{|l|}{ Age at study entry (years)*: } \\
\hline Mean (SD) & $45(9)$ & $44(10)$ \\
\hline Range & $26-64$ & $27-62$ \\
\hline \multicolumn{3}{|c|}{ First onset of back pain (months ago)* } \\
\hline Mean (SD) & $98(106)$ & $93(125)$ \\
\hline Range & $6-600$ & $6-384$ \\
\hline \multicolumn{3}{|c|}{ This episode of back pain (months)*: } \\
\hline Mean (SD) & $23(49)$ & $19(29)$ \\
\hline Range & $6-156$ & $6-240$ \\
\hline \multicolumn{3}{|l|}{ Drug treatment } \\
\hline \multicolumn{3}{|l|}{ Drugs for pain: } \\
\hline NSAIDS & $43(64)$ & $34(50)$ \\
\hline Week opioids & $6(9)$ & $4(6)$ \\
\hline Strong opioids & $7(10)$ & $6(9)$ \\
\hline \multicolumn{3}{|l|}{ Adjuvant drug treatments: } \\
\hline Antidepressants & $3(4)$ & $3(4)$ \\
\hline Muscle relaxants & $1(1)$ & $1(1)$ \\
\hline Anticonvulsives & $3(4)$ & $0(0)$ \\
\hline Glucocorticoids & $1(1)$ & $0(0)$ \\
\hline \multicolumn{3}{|c|}{ Drug treatments taken for other conditions: } \\
\hline Cardiovascular & $9(13)$ & $9(13)$ \\
\hline Asthma & $3(4)$ & $2(3)$ \\
\hline Thyroid & $1(1)$ & $1(1)$ \\
\hline Restless legs & $1(1)$ & $0(0)$ \\
\hline Hormone replacement & $3(4)$ & $1(1)$ \\
\hline Malaria & $1(1)$ & $0(0)$ \\
\hline $\begin{array}{l}\text { NSAIDS=non-steroid anti-inf } \\
{ }^{*} \text { No significant difference (P }\end{array}$ & & \\
\hline
\end{tabular}

and Oswestry disability index are reported in appendices 1 and 2.

The analysis of secondary outcome measures at the primary endpoints (table 5) and throughout the trial showed results similar to pain and Oswestry disability index: both groups improved slightly during the stimulation period and significantly after the cognitive behavioural management (within group changes). Multilevel models for all secondary outcome measures showed that there were no significant differences between groups at any time point.

The success of blinding was based on ratings from 587 participants (one rating per participant per day of stimulation). Three quarters of ratings $(n=442)$ indicated that participants believed they had received anodal stimulation. As agreement was poor to slight, participants were effectively blinded throughout the trial (table 6 ). The $\kappa$ coefficient for correctly guessed treatment groups was $\kappa=0.103$. This result is translated as slight agreement and thereby indicating effective investigator blinding. ${ }^{77}$

\section{Discussion}

Five days of anodal transcranial direct current stimulation compared with sham stimulation did not result in a reduction of the perceived intensity or level of disability in non-specific chronic low back pain. Trial results did not support the pain reducing effect of transcranial direct current stimulation on chronic pain as reported by previously published trials or the small combined effect size identified in systematic reviews and meta-analyses. ${ }^{2627}$ Furthermore, transcranial direct current stimulation preceding cognitive behavioural management did not influence the reduction of pain and disability levels after the behavioural management.

This trial was specifically designed to evaluate the effectiveness of transcranial direct current stimulation on pain and disability in non-specific chronic low back pain and the adjuvant effects of transcranial direct current stimulation on cognitive behavioural management. The study population was carefully selected with clear inclusion/exclusion criteria to achieve a level of homogeneity that reflected the typical participants of a cognitive behavioural management programme. This allows us to generalise our results to other cognitive behavioural management settings.

As critiqued in our systematic review, ${ }^{27}$ all previous published trials have been limited by small sample sizes. Sample size calculations (if reported) were based on transcranial magnetic stimulation studies with large effect sizes and small standard deviations ${ }^{61}$ or on previous publications of equally underpowered studies. ${ }^{29}$ Small sample sizes and risk of bias issues identified by systematic reviews ${ }^{2627}$ reduce the confidence in such reported effect sizes for pain reduction after transcranial direct current stimulation. The current trial is the only trial to date on transcranial direct current stimulation that included a sufficient number of participants to show an effect on pain, based on a valid calculation of sample size.

\section{Results in context}

Furthermore, this is the first randomised controlled trial to exclusively investigate the effect of transcranial direct current stimulation on non-specific chronic low back pain. Two previous trials on transcranial direct current stimulation for the reduction of chronic pain included some participants with chronic low back pain. Antal and colleagues investigated a mixed population of 23 patients with chronic pain that included eight with chronic low back pain. ${ }^{78}$ Results indicated a significant pain reducing effect in the group that received anodal stimulation. Only five patients with chronic low back pain, however, received both anodal and sham stimulation. As these patients were not analysed separately, we could not distinguish the effect of anodal transcranial direct current stimulation on chronic low back pain from the overall effect. ${ }^{78}$ A second exploratory study focused on the reduction of non-specific chronic low back pain and found no effect of transcranial direct current stimulation over sham stimulation. ${ }^{79}$ The study included eight participants and followed an interrupted time series design in which participants received sham stimulation until a randomly allocated day, when the stimulation changed to anodal mode. This method resulted in a minimum of three and a maximum of 15 stimulation sessions per patient. This design did not allow the evaluation of a specific stimulation paradigm, 
Table 2 | Baseline data on primary and secondary outcome measures by intervention group in trial of effectiveness of anodal or sham transcranial direct current stimulation (tDCS) preceding cognitive behavioural management (CBT) for patients with chronic low back pain*

\begin{tabular}{|c|c|c|}
\hline & \multicolumn{2}{|c|}{ Intervention group } \\
\hline & Anodal $(n=67)$ & Sham $(n=68)$ \\
\hline \multicolumn{3}{|l|}{ Primary outcome measures } \\
\hline Mean (SD) VAS (0-100 mm) & $48(21)$ & $48(18)$ \\
\hline Range & $15-89$ & $15-84$ \\
\hline Mean (SD) ODI (0-50 points) & $17(6)$ & $15(5)$ \\
\hline Range & $8-32$ & $8-29$ \\
\hline \multicolumn{3}{|l|}{ Secondary outcome measures } \\
\hline Mean (SD) FABQ physical activity (0-24 points) & $14(4)$ & $15(7)$ \\
\hline Range & $7-20$ & $2-24$ \\
\hline Mean (SD) FABQ work (0-42 points) & $21(11)$ & $23(10)$ \\
\hline Range & $2-42$ & $9-40$ \\
\hline Mean (SD) FfBH (12-36 points) & $22(4)$ & $21(4)$ \\
\hline Range & 12,29 & 12,33 \\
\hline Mean (SD) HADS anxiety (0-21 points) & $7(4)$ & $6(4)$ \\
\hline Range & $0-15$ & $0-18$ \\
\hline Mean (SD) HADS depression (0-21 points) & $6(4)$ & $6(4)$ \\
\hline Range & $0-15$ & $0-14$ \\
\hline \multicolumn{3}{|l|}{ RAND-36 (0-100\%): } \\
\hline Mean (SD) physical functioning & $54(19)$ & $58(23)$ \\
\hline Range & $0-90$ & $10-100$ \\
\hline Mean (SD) role limitations from physical health & $19(28)$ & $15(28)$ \\
\hline Range & $0-100$ & $0-100$ \\
\hline Mean (SD) pain & $31(16)$ & $32(12)$ \\
\hline Range & $0-74$ & $0-52$ \\
\hline Mean (SD) general health & $50(17)$ & $54(19)$ \\
\hline Range & $15-92$ & $20-100$ \\
\hline Mean (SD) energy / fatigue & $38(19)$ & $44(18)$ \\
\hline Range & $0-85$ & $10-85$ \\
\hline Mean (SD) social functioning & $56(26)$ & $61(26)$ \\
\hline Range & $0-100$ & $0-100$ \\
\hline Mean (SD) role limitations from emotional problems & $51(43)$ & $49(43)$ \\
\hline Range & $0-100$ & $0-100$ \\
\hline Mean (SD) emotional wellbeing & $58(19)$ & $60(18)$ \\
\hline Range & $20-96$ & $24-92$ \\
\hline Median (range) bothersomeness (0-4 points) & $3(2-4)$ & $3(2-4)$ \\
\hline Interquartile range & $3-4$ & $3-4$ \\
\hline
\end{tabular}

especially as stimulation was applied with varying gaps between sessions of up to six days. The small sample size was a further limitation; hence the effectiveness of transcranial direct current stimulation on non-specific chronic low back pain could not be evaluated.

Five days of anodal stimulation did not result in a significant reduction of the disability associated with non-specific chronic low back pain. Two trials on transcranial direct current stimulation for the reduction of

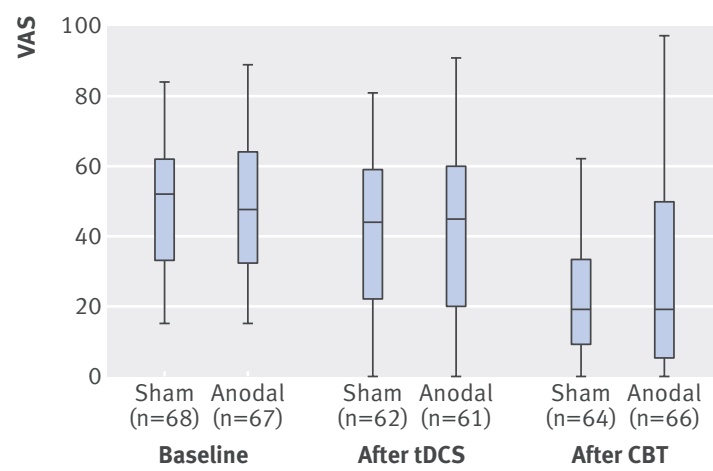

Fig 3 | Box plot of visual analogue scale (VAS) pain values at baseline and primary endpoints (after anodal or sham transcranial direct current stimulation (tDCS) and after cognitive behavioural management (CBT)) for patients with chronic low back pain

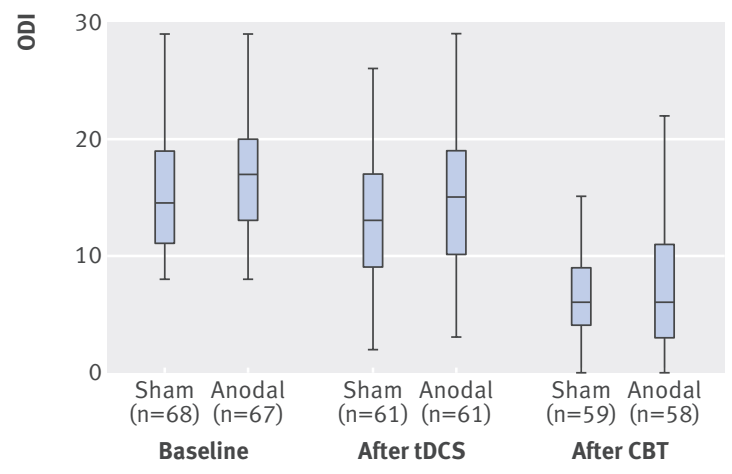

Fig 4 | Box plot of Oswestry disability index (ODI) values at baseline and primary endpoints (after anodal or sham transcranial direct current stimulation (tDCS) and after cognitive behavioural management (CBT)) for patients with chronic low back pain

pain evaluated disability with the Roland Morris disability questionnaire as a secondary outcome. In a crossover trial in seven participants with chronic pelvic pain, Fenton and colleagues found a reduction of 0.83 out of 24 points that was significant but not clinically relevant. ${ }^{80}$ A second trial in eight participants resulted in a reduction of 0.5 points in the sham group and 1.7 points in the anodal stimulation group. ${ }^{79}$ Results were not analysed for significance between groups, and recommended minimum clinically relevant levels of change in the Roland Morris disability questionnaire of 4-5 points ${ }^{5960}$ were not met.

One previous trial applied transcranial direct current stimulation in combination with a multidisciplinary intervention for the reduction of fibromyalgia pain. ${ }^{30}$ Twenty three patients were randomly assigned to

Table 3 | Mean (SD) values and results from analysis of covariance (ANCOVA) for visual analogue scale (VAS) for pain and Oswestry disability index (ODI) after stimulation and after cognitive behavioural management with $99 \%$ confidence intervals for differences between groups

\begin{tabular}{|c|c|c|c|c|c|c|c|c|}
\hline \multirow[b]{2}{*}{$\begin{array}{l}\text { Outcome } \\
\text { measure }\end{array}$} & \multicolumn{4}{|c|}{ After stimulation } & \multicolumn{4}{|l|}{ After CBT } \\
\hline & $\begin{array}{l}\text { Mean (SD) } \\
\text { anodal }\end{array}$ & $\begin{array}{l}\text { Mean (SD) } \\
\text { sham }\end{array}$ & $\begin{array}{l}\text { Mean difference between } \\
\text { groups }(99 \% \mathrm{Cl})\end{array}$ & $P$ value & $\begin{array}{l}\text { Mean (SD) } \\
\text { anodal }\end{array}$ & $\begin{array}{l}\text { Mean (SD) } \\
\text { sham }\end{array}$ & $\begin{array}{l}\text { Mean difference between } \\
\text { groups }(99 \% \mathrm{Cl})\end{array}$ & $P$ value \\
\hline VAS (mm) & $42(24), n=60$ & $41(23), n=62$ & 1 (-8.69 to 6.3$)$ & 0.68 & $26(23), n=60$ & $23(18), n=58$ & $3(-10.32$ to 6.73$)$ & 0.58 \\
\hline ODI (points) & $15(7), n=61$ & $14(6), n=61$ & $1(-1.73$ to 1.98$)$ & 0.86 & $7(6), n=53$ & $7(5), n=54$ & $0(-2.45$ to 2.62$)$ & 0.92 \\
\hline
\end{tabular}




\begin{tabular}{|c|c|c|c|c|c|}
\hline \multirow[b]{2}{*}{ Outcome measure and group } & \multicolumn{3}{|c|}{ Mean (SD) score by time after CBT } & \multirow{2}{*}{$\begin{array}{l}95 \% \mathrm{Cl} \text { for estimates of } \\
\text { group*time }\end{array}$} & \multirow{2}{*}{$\begin{array}{l}\text { P value for group }{ }^{\star} \text { time } \\
\text { interaction }\end{array}$} \\
\hline & 4 weeks & 12 weeks & 24 weeks & & \\
\hline \multicolumn{6}{|l|}{ Visual analogue scale for pain } \\
\hline Sham & $23(23), n=56$ & $22(22), n=48$ & $22(21), n=42$ & \multirow{2}{*}{-0.84 to 0.20} & \multirow{2}{*}{0.23} \\
\hline Anodal & $26(26), n=54$ & $27(26), n=53$ & $29(26), n=47$ & & \\
\hline \multicolumn{6}{|l|}{ Oswestry disability index } \\
\hline Sham & $7(6), n=56$ & $6(6), n=49$ & $7(6), n=42$ & \multirow{2}{*}{-0.16 to 0.11} & \multirow{2}{*}{0.72} \\
\hline Anodal & $8(7), n=56$ & $9(7), n=52$ & $9(7), n=48$ & & \\
\hline
\end{tabular}

Table 5 | Mean (SD) values and results from analysis of covariance (ANCOVA) for all secondary outcome measures after stimulation and after cognitive behavioural management (CBT)

\begin{tabular}{|c|c|c|c|c|c|c|c|c|}
\hline & \multicolumn{4}{|c|}{ After stimulation } & \multicolumn{4}{|l|}{ After CBT } \\
\hline & $\begin{array}{l}\text { Mean (SD) } \\
\text { anodal }\end{array}$ & $\begin{array}{l}\text { Mean (SD) } \\
\text { sham }\end{array}$ & $\begin{array}{l}95 \% \mathrm{Cl} \text { for differences } \\
\text { between groups }\end{array}$ & $P$ values & $\begin{array}{l}\text { Mean (SD) } \\
\text { anodal }\end{array}$ & $\begin{array}{l}\text { Mean (SD) } \\
\text { sham }\end{array}$ & $\begin{array}{l}95 \% \mathrm{Cl} \text { for differences } \\
\text { between groups }\end{array}$ & $P$ values \\
\hline \multicolumn{9}{|l|}{ FABQ: } \\
\hline Physical activity & $15(4), n=62$ & $15(4), n=61$ & -3.24 to 3.14 & 0.98 & $9(4), n=54$ & $10(7), n=55$ & -4.75 to 5.32 & 0.91 \\
\hline Work & $21(12), n=62$ & $21(12), n=61$ & -5.92 to 4.74 & 0.82 & $16(9), n=54$ & 14 (11), $n=55$ & -8.47 to 5.96 & 0.72 \\
\hline $\mathrm{FfBH}$ & $21(4), n=62$ & $20(5), n=61$ & -0.70 to 1.39 & 0.51 & $16(4), n=54$ & $16(4), n=55$ & -1.58 to1.11 & 0.73 \\
\hline \multicolumn{9}{|l|}{ HADS: } \\
\hline Anxiety & $7(4), n=59$ & $6(4), n=58$ & -0.95 to 0.51 & 0.56 & $5(4), n=52$ & $4(3), n=52$ & -1.10 to 0.88 & 0.83 \\
\hline Depression & $6(4), n=59$ & $6(4), n=57$ & -1.10 to 0.69 & 0.65 & $4(4), n=52$ & $4(3), n=51$ & -0.85 to 1.15 & 0.77 \\
\hline Bothersomeness & $3(1), n=61$ & $3(1), n=61$ & -0.18 to 0.30 & 0.63 & $2(1), n=54$ & $2(1), n=55$ & -0.47 to 0.30 & 0.67 \\
\hline PPSI & $1(1), n=61$ & $2(1), n=61$ & -0.29 to 0.55 & 0.54 & $3(1), n=54$ & $3(1), n=55$ & -0.57 to 0.21 & 0.36 \\
\hline \multicolumn{9}{|l|}{ RAND-36: } \\
\hline Physical activity & $57(19), n=62$ & 62 (21), $n=61$ & -2.64 to 8.45 & 0.30 & $81(19), n=58$ & 85 (18), n=59 & -3.51 to 8.64 & 0.41 \\
\hline $\begin{array}{l}\text { Role limitations from } \\
\text { physical health }\end{array}$ & $23(32), n=61$ & 21 (32), $n=61$ & -5.90 to 11.53 & 0.52 & $53(46), n=53$ & 59 (44), $n=54$ & -7.09 to 23.71 & 0.29 \\
\hline Pain & $33(13), n=61$ & $33(14), n=61$ & -3.12 to 4.35 & 0.77 & 49 (18), $n=53$ & $53(17), n=55$ & -1.44 to 11.31 & 0.13 \\
\hline General health & $52(19), n=58$ & $55(19), n=61$ & -5.52 to 4.37 & 0.82 & $60(20), n=53$ & $63(21), n=55$ & -5.36 to 5.54 & 0.97 \\
\hline Energy/fatigue & $43(20), n=59$ & $47(18), n=61$ & -7.02 to 2.87 & 0.41 & $56(16), n=54$ & 58 (19), $n=54$ & -4.59 to 6.87 & 0.69 \\
\hline Social functioning & $59(26), n=62$ & $64(28), n=59$ & -3.82 to 7.24 & 0.54 & $77(22), n=54$ & $75(22), n=53$ & -13.25 to 0.88 & 0.09 \\
\hline $\begin{array}{l}\text { Role limitations from } \\
\text { emotional problems }\end{array}$ & $47(45), n=62$ & 52 (46), $n=61$ & -3.62 to 21.13 & 0.16 & 70 (42), $n=54$ & 78 (37), $n=54$ & -5.78 to 19.53 & 0.28 \\
\hline Emotional wellbeing & 60 (19), $n=60$ & $63(17), n=60$ & -1.83 to 5.83 & 0.30 & $73(18), n=53$ & $73(16), n=53$ & -7.89 to 2.03 & 0.24 \\
\hline
\end{tabular}

weekly active and sham stimulation sessions for 10 weeks during a multidisciplinary intervention. No effect for pain was found, and disability was not measured.

Compared with sham stimulation, however, anodal stimulation was associated with a significant effect on the SF-36 subscale for pain. This effect should be interpreted with caution as the sample size calculation was based on a large effect size of $3 \mathrm{~cm}$ on a $0-10 \mathrm{~cm}$ visual analogue scale and standard deviations of 2.5. Furthermore, two outcome measures were presented (but not defined a priori) in the results section at an $\alpha$ level of 0.05 and a power of $80 \%$. No adjustments for multiple testing were made.

Neurophysiological explanations for the lack of a treatment effect can only be hypothesised. Top down pain inhibition is the most described working mechanism for transcranial direct current stimulation. ${ }^{81} 82$ It is also known as central pain modulation and relies on the concept that altered cortical activity leads to a descending cascade of events consequently resulting in pain relief. ${ }^{83}$ The primary motor cortex is the origin of the descending corticothalamic pathway. Polania and colleagues found an increased functional coupling of the motor cortex and the thalamus after anodal transcranial direct current stimulation over the primary motor cortex ${ }^{84}$ and further evidence suggested a spreading of electrical currents to subcortical areas distant from the stimulation site. ${ }^{85} 86$ Modulation of the $\mathrm{H}$ reflex in the quadriceps muscle indicated that the effects of transcranial direct current stimulation descended as far down as the leg via the spinal pathway in healthy participants. ${ }^{87}$ But evidence that these remote effects lead to pain reduction relied on studies with controversial results using experimental pain or pain thresholds. ${ }^{45} 6488-92$ In summary, there is sufficient

Table 6 | Effectiveness of blinding of participants in trial of effectiveness of anodal or sham transcranial direct current stimulation preceding cognitive behavioural management for patients with chronic low back pain

\begin{tabular}{|c|c|c|c|c|c|}
\hline & Day $1(n=112)$ & Day $2(n=120)$ & Day $3(n=124)$ & Day $4(\mathrm{n}=118)$ & Day $5(n=120)$ \\
\hline Agreement between guessed and received stimulation & $\kappa=0.111$ & $\kappa=0.000$ & $\kappa=-0.014$ & $\kappa=-0.007$ & $\kappa=-0.120$ \\
\hline Interpretation (Landis and Koch ${ }^{77}$ ) & Slight agreement & Slight agreement & Poor agreement & Poor agreement & Poor agreemen \\
\hline
\end{tabular}


evidence to support a reliable cortical and subcortical neurophysiological response to transcranial direct current stimulation but alterations in pain perception were absent or inconsistent.

\section{Limitations}

A limitation of this trial is that it was conducted at one study centre. The sample of patients with non-specific chronic low back pain, however, is representative for international cognitive behavioural management settings regarding baseline demographic data and baseline clinical variables. ${ }^{62727374}$ A further limitation could be that transcranial direct current stimulation was applied before cognitive behavioural management. We cannot exclude a beneficial effect of transcranial direct current stimulation on non-specific chronic low back pain applied during cognitive behavioural management, although Riberto and colleagues evaluated transcranial direct current stimulation applied during a multidisciplinary intervention and found no effect on pain in patients with fibromyalgia. ${ }^{30}$

In conclusion, we have shown that transcranial direct current stimulation alone or in combination with cognitive behavioural management is inefficient for the reduction of pain and disability in patients with non-specific chronic low back pain.

Contributors: All authors substantially contributed to the trial and its reporting, approved of the final version of the manuscript and agree to be accountable for all aspects of the work. KL contributed to the literature search, study design, data collection, data analysis, data interpretation, figures, and writing. AR contributed to the overview methodological quality, study design, data interpretation, and writing. CW contributed to the study design, data interpretation, data analysis, and writing. TJ contributed to the literature search and study design. AP helped with data collection. GM contributed to the study design. AM contributed to the literature search, study design, data interpretation, writing, and financing and was guarantor.

Funding: This study was funded by the Deutsche Forschungsgemeinschaft DFG (MA 1862/10-1).

Competing interests: All authors have completed the ICMIE uniform disclosure form at www.icmje.org/coi_disclosure.pdf and declare: AM, TJ, KL, and AP had financial support from DFG (MA 1862/10-1) and NeurolmageNord for the submitted work.

Ethical approval: This study was approved by the German ethics authorities (PV 3297) and the University of Birmingham research ethics committee (ERN_10-0863).

Data sharing: Statistical code and dataset (anonymised patient data) are available from the corresponding author.

Transparency: The lead author affirms that the manuscript is an honest, accurate, and transparent account of the study being reported; that no important aspects of the study have been omitted; and that any discrepancies are disclosed.

This is an Open Access article distributed in accordance with the Creative Commons Attribution Non Commercial (CC BY-NC 4.0) license, which permits others to distribute, remix, adapt, build upon this work non-commercially, and license their derivative works on different terms, provided the original work is properly cited and the use is noncommercial. See: http://creativecommons.org/licenses/by-nc/4.0/.

1 Becker A, Held H, Redaelli M, et al. Low back pain in primary care: costs of care and prediction of future health care utilization. Spine 2010;35:1714-20.

2 Henschke N, Maher CG, Refshauge KM, et al. Prevalence of and screening for serious spinal pathology in patients presenting to primary care settings with acute low back pain. Arthritis Rheum 2009;60:3072-80.

3 Chou R, Shekelle P. Will this patient develop persistent disabling low back pain? JAMA 2010:303:1295-02.

4 Grotle M, Brox JI, Veierod MB, et al. Clinical course and prognostic factors in acute low back pain: patients consulting primary care for the first time Spine 2005:30:976-82.
5 Gurcay E, Bal A, Eksioglu E, et al. Acute low back pain: clinical course and prognostic factors. Disabil Rehabil 2009;31:840-5.

6 Henschke N, Maher CG, Refshauge KM, et al. Prognosis in patients with recent onset low back pain in Australian primary care: inception cohort study. BMJ 2008;337:a171.

7 Balague F, Mannion AF, Pellise F, et al. Non-specific low back pain. Lancet 2011:379:482-91.

8 Airaksinen O, Brox Jl, Cedraschi C, et al. Chapter 4. European guidelines for the management of chronic nonspecific low back pain. Eur Spine /2006;:S192-300.

9 Latremoliere A, Woolf CJ. Central sensitization: a generator of pain hypersensitivity by central neural plasticity. J Pain 2009;10:895-926.

10 Woolf C). Central sensitization: implications for the diagnosis and treatment of pain. Pain 2011;152:S2-15

11 Apkarian AV, Baliki MN, Geha PY. Towards a theory of chronic pain. Prog Neurobiol 2009;87:81-97.

12 Zhang L, Zhang Y, Zhao ZQ. Anterior cingulate cortex contributes to the descending facilitatory modulation of pain via dorsal reticular nucleus. Eur J Neurosci 2005;22:1141-8.

13 Beck JS. Cognitive behavior therapy: basics and beyond. 2nd ed. Guilford Press, 2011:19-20.

14 Koes BW, van Tulder M, Lin CW, et al. An updated overview of clinical guidelines for the management of non-specific low back pain in primary care. Eur Spine /2010;19:2075-94.

15 Lambert M. ICSI releases guideline on chronic pain assessment and management. Am Fam Physician 2010;82:434-9.

16 Savigny P, Watson P, Underwood M. Early management of persistent non-specific low back pain: summary of NICE guidance. $B M$ J 2009;338:b1805.

17 Van Middelkoop M, Rubinstein SM, Kuijpers T, et al. A systematic review on the effectiveness of physical and rehabilitation interventions for chronic non-specific low back pain. Eur Spine J 2011;20:19-39.

18 Moseley GL, Flor H. Targeting cortical representations in the treatment of chronic pain: a review. Neurorehabil Neural Repair 2012;26:646-52.

19 Wand BM, O'Connell NE Chronic non-specific low back pain-subgroups or a single mechanism? BMC Musculoskelet Disord 2008;9:11.

20 Wand BM, Parkitny L, O'Connell NE, et al. Cortical changes in chronic low back pain: current state of the art and implications for clinical practice Man Ther 2011:16:15-20.

21 Nitsche MA, Cohen LG, Wassermann EM, et al. Transcranial direct current stimulation: state of the art 2008. Brain Stimul Brain Stimul 2008;1:206-23.

22 Holsheimer J, Nguyen JP, Lefaucheur JP, et al. Cathodal, anodal or bifocal stimulation of the motor cortex in the management of chronic pain? Acta Neurochir Suppl 2007;97:57-66.

23 DosSantos MF, Love TM, Martikainen IK, et al. Immediate effects of tDCS on the mu-opioid system of a chronic pain patient. Front Psychiatry 2012;3:93.

24 Garcia-Larrea L, Peyron R. Motor cortex stimulation for neuropathic pain: From phenomenology to mechanisms. Neuroimage 2007;37:S71-9.

25 Pagano RL, Assis DV, Clara JA, et al. Transdural motor cortex stimulation reverses neuropathic pain in rats: a profile of neuronal activation. Eur I Pain 2011:15:268 e1-14

26 O'Connell NE, Wand BM, Marston L, et al. Non-invasive brain stimulation techniques for chronic pain. Cochrane Database Syst Rev 2014:4:CD008208.

27 Luedtke K, Rushton A, Wright C, et al. Transcranial direct current stimulation for the reduction of clinical and experimentally induced pain: a systematic review and meta-analysis. Clin J Pain 2012;28:452-61

28 Cosentino G, Fierro B, Paladino P, et al. Transcranial direct current stimulation preconditioning modulates the effect of high-frequency repetitive transcranial magnetic stimulation in the human moto cortex. Eur J Neurosci 2012;35:119-24.

29 Boggio PS, Amancio EJ, Correa CF, et al. Transcranial DC stimulation coupled with TENS for the treatment of chronic pain: a preliminary study. Clin J Pain 2009;25:691-5.

30 Riberto M, Marcon Alfieri F, Monteiro de Benedetto Pacheco K, et al. Efficacy of transcranial direct current stimulation coupled with a multidisciplinary rehabilitation program for the treatment of fibromyalgia. Open Rheumatol / 2011;5:45-50.

31 Schulz KF, Altman DG, Moher D. CONSORT 2010 statement: updated guidelines for reporting parallel group randomised trials. Int J Surg. 2010;9:672-7.

32 International Conference on Harmonisation of Technical Requirements for Registration of Pharmaceuticals for Human Use. Guideline for good clinical practice www.ich.org/fileadmin/ Public_Web_Site/ICH_Products/Guidelines/Efficacy/E6/ E6_R1_Guideline.pdf.

33 World Medical Association. Declaration of Helsinki. www.wma.net/e/ ethicsunit/helsinki.htm.

34 Altman DG, Bland JM. How to randomise. BMJ 1999;319:703-4.

35 Herbert RD. Randomisation in clinical trials. Aust) Physiother 2005:51:58-60. 
36 Meinert CL. Clinical trials: design, conduct, and analysis. Oxford University Press, 1986

37 Schulz KF, Grimes DA. Generation of allocation sequences in randomised trials: chance, not choice. Lancet 2002;359:515-9.

38 Zelman DC, Hoffman DL, Seifeldin R, et al. Development of a metric for a day of manageable pain control: derivation of pain severity cut-points for low back pain and osteoarthritis. Pain 2003;106:35-42.

39 Gandiga PC, Hummel FC, Cohen LG. Transcranial DC stimulation (tDCS): a tool for double-blind sham-controlled clinical studies in brain stimulation. Clin Neurophysiol 2006;117:845-50.

40 Loo CK, Sachdev P, Martin D, et al. A double-blind, sham-controlled trial of transcranial direct current stimulation for the treatment of depression. Int / Neuropsychopharmacol 2010;13:61-9.

41 Priori A, Hallett M, Rothwell JC. Repetitive transcranial magnetic stimulation or transcranial direct current stimulation. Brain Stimulation 2009;2:241-5.

42 O'Connell NE, Cossar J, Marston L, et al. Rethinking clinical trials of transcranial direct current stimulation: participant and assessor blinding is inadequate at intensities of 2mA. PLoS One 2012;7:e47514.

43 Landis JR, Koch GG. An application of hierarchical kappa-type statistics in the assessment of majority agreement among multiple observers. Biometrics 1977;33:363-74

44 Ambrus GG, Al-Moyed H, Chaieb L, et al. The fade-in-short stimulation-fade out approach to sham tDCS-reliable at $1 \mathrm{~mA}$ for naive and experienced subjects, but not investigators. Brain Stimul 2012;5:499-504

45 Jurgens TP, Schulte A, Klein T, et al. Transcranial direct current stimulation does neither modulate results of a quantitative sensory testing protocol nor ratings of suprathreshold heat stimuli in healthy volunteers. Eur J Pain 2012;16:1251-63.

46 Ihle K, Rodriguez-Raecke R, Luedtke K, et al. tDCS modulates cortical nociceptive processing but has little impact on pain perception. Pain 2014;155:2080-7.

47 McCracken LM, Turk DC. Behavioral and cognitive-behavioral treatment for chronic pain: outcome, predictors of outcome, and treatment process. Spine 2002;27:2564-73.

48 Scascighini L, Toma V, Dober-Spielmann S, et al. Multidisciplinary treatment for chronic pain: a systematic review of interventions and outcomes. Rheumatology 2008;47:670-8

49 Turk DC. Clinical effectiveness and cost-effectiveness of treatments for patients with chronic pain. Clin J Pain 2002;18:355-65.

50 Turk DC, Dworkin RH, Allen RR, et al. Core outcome domains for chronic pain clinical trials: IMMPACT recommendations. Pain 2003;106:337-45.

51 Kohlmann T, Raspe H. [Hannover functional questionnaire in ambulatory diagnosis of functional disability caused by backache] Rehabilitation (Stuttg) 1996;35:I-VIII.

52 Dunn KM, Croft PR. Classification of low back pain in primary care: using "bothersomeness" to identify the most severe cases. Spine 2005;30:1887-92

53 Hays RD, Sherbourne CD, Mazel RM. The RAND 36-item health Survey 1.0. Health Econ 1993;2:217-27.

54 Pfingsten M, Kroner-Herwig B, Leibing E, et al. Validation of the German version of the fear-avoidance beliefs questionnaire (FABQ). EurJ Pain 2000;4:259-66.

55 Hinz A, Zweynert U, Kittel ], et al. [Measurement of change with the Hospital Anxiety and Depression Scale (HADS): sensitivity and reliability of change]. Psychother Psychosom Med Psychol 2009;59:394-400.

56 Ten Klooster PM, Drossaers-Bakker KW, Taal E, et al. Patient-perceived satisfactory improvement (PPSI): interpreting meaningful change in pain from the patient's perspective. Pain 2006;121:151-7.

57 Cleophas TJ, Zwinderman AH. Clinical trials are often false positive: review of simple methods to control this problem. Curr Clin Pharmacol 2006;1:1-4

58 Neuhäuser M. How to deal with multiple endpoints in clinical trials. Fundam Clin Pharmacol 2006:20:515-23.

59 Ostelo RW, Deyo RA, Stratford P, et al. Interpreting change scores for pain and functional status in low back pain: towards international consensus regarding minimal important change. Spine 2008:33:90-4

60 Maughan EF, Lewis JS. Outcome measures in chronic low back pain. Eur Spine / 2010;19:1484-94.

61 Fregni F, Boggio PS, Lima MC, et al. A sham-controlled, phase II trial of transcranial direct current stimulation for the treatment of central pain in traumatic spinal cord injury. Pain 2006;122:197-209.

62 Lamb SE, Hansen Z, Lall R, et al. Group cognitive behavioural treatment for low-back pain in primary care: a randomised controlled trial and cost-effectiveness analysis. Lancet 2010;375:916-23.

63 Cohen J. A power primer. Psychol Bull. 1992;112:155-9

64 Luedtke K, May A, Jurgens TP. No effect of a single session of transcranial direct current stimulation on experimentally induced pain in patients with chronic low back pain-an exploratory study. PLoS One 2012;7:e48857.

65 Turk DC, Dworkin RH, McDermott MP, et al. Analyzing multiple endpoints in clinical trials of pain treatments: IMMPACT recommendations. Initiative on methods, measurement, and pain assessment in clinical trials. Pain 2008:139:485-93.
66 Twisk J, Proper K. Evaluation of the results of a randomized controlled trial: how to define changes between baseline and follow-up. J Clin Epidemiol 2004:57:223-8.

67 Vickers AJ, Altman DG. Statistics notes: analysing controlled trials with baseline and follow up measurements. BMJ 2001;323:1123-4.

68 Field A. Discovering statistics using SPSS. 3rd ed. Sage Publications, 2009.

69 Draper N, Smith H. Applied regression analysis. 2nd ed. John Wiley, 1981

70 Twisk J, de Boer M, de Vente W, et al. Multiple imputation of missing values was not necessary before performing a longitudina mixed-model analysis. / Clin Epidemiol 2013:66:1022-8

71 Moher D, Liberati A, Tetzlaff J, et al. Preferred reporting items for systematic reviews and meta-analyses: the PRISMA statement. / Clin Epidemiol 2009;62:1006-12.

72 Vibe Fersum K, O'Sullivan P, Skouen J, et al. Efficacy of classificationbased cognitive functional therapy in patients with non-specific chronic low back pain: a randomized controlled trial. Eur J Pain 2013;17:916-28.

73 Lang E, Liebig K, Kastner S, v. Multidisciplinary rehabilitation versus usual care for chronic low back pain in the community: effects on quality of life. Spine / 2003;3:270-6.

74 Kääpä EF, Sarna K, Malmivaara S. Multidisciplinary group rehabilitation versus individual physiotherapy for chronic nonspecific low back pain. Spine 2008;31:371-6.

75 Polit DF, Gillespie BM. The use of the intention-to-treat principle in nursing clinical trials. Nurs Res 2009:58:391-9.

76 Polit DF, Gillespie BM. Intention-to-treat in randomized controlled trials: recommendations for a total trial strategy. Res Nurs Health 2010;33:355-68.

77 Landis JR, Koch GG. The measurement of observer agreement for categorical data. Biometrics 1977;33:159-74

78 Antal A, Terney D, Kuhnl S, et al. Anodal transcranial direct current stimulation of the motor cortex ameliorates chronic pain and reduces short intracortical inhibition. J Pain Symptom Manage 2010;39:890-903.

79 O'Connell NE, Cossar J, Marston L, et al. Transcranial direct current stimulation of the motor cortex in the treatment of chronic nonspecific low back pain: a randomized, double-blind exploratory study. Clin J Pain 2013;29:26-34.

80 Fenton BW, Palmieri PA, Boggio P, et al. A preliminary study of transcranial direct current stimulation for the treatment of refractory chronic pelvic pain. Brain Stimulation 2009;2:103-7.

81 Knotkova H, Nitsche MA, Cruciani RA. Putative physiological mechanisms underlying tDCS analgesic effects. Front Hum Neurosci 2013;7:628.

82 Medeiros LF, de Souza IC, Vidor LP, et al. Neurobiological effects of transcranial direct current stimulation: a review. Front Psychiatry 2012;3:110.

83 Ossipov MH, Dussor GO, Porreca F. Central modulation of pain. J Clin Invest 2010;120:3779-87.

84 Polania R, Paulus W, Nitsche MA. Modulating cortico-striatal and thalamo-cortical functional connectivity with transcranial direct current stimulation. Hum Brain Mapp 2011;33:2499-508.

85 Lang N, Nitsche MA, Paulus W, et al. Effects of transcranial direct current stimulation over the human motor cortex on corticospinal and transcallosal excitability. Exp Brain Res 2004;156:439-43.

86 Reidler IS, Mendonca ME, Santana MB, et al. Effects of motor cortex modulation and descending inhibitory systems on pain thresholds in healthy subjects. J Pain 2012;13:450-8.

87 Roche N, Lackmy A, Achache V, et al. Effects of anodal tDCS on lumbar propriospinal system in healthy subjects. Clin Neurophysiol 2011;123:1027-34

88 Antal A, Brepohl N, Poreisz C, et al. Transcranial direct current stimulation over somatosensory cortex decreases experimentally induced acute pain perception. Clin I Pain 2008;24:56-63.

89 Boggio PS, Zaghi S, Lopes M, et al. Modulatory effects of anodal transcranial direct current stimulation on perception and pain thresholds in healthy volunteers. Eur / Neurol 2008:15:1124-30.

90 Csifcsak G, Antal A, Hillers F, et al. Modulatory effects of transcranial direct current stimulation on laser-evoked potentials. Pain Med 2009;10:122-32

91 Bachmann CG, Muschinsky S, Nitsche MA, et al. Transcranial direct current stimulation of the motor cortex induces distinct changes in thermal and mechanical sensory percepts. Clin Neurophysiol 2011;121:2083-9.

92 Grundmann L, Rolke R, Nitsche MA, et al. Effects of transcranial direct current stimulation of the primary sensory cortex on somatosensory perception. Brain Stimul 2011;4:253-60.

(c) BMJ Publishing Group Ltd 2015

Appendix 1: Stepwise building of mixed model for visual analogue scale over all time points

Appendix 2: Stepwise building of mixed model for Oswestry disability index over all time points 